\title{
Optimization of the extraction of phenolic compounds and antioxidant activity from the roots of Waltheria ovata using the response surface methodology
}

\author{
${ }^{1, *}$ Herrera-Calderon, O. and ${ }^{2}$ Vega, R. \\ ${ }^{1}$ Department of Pharmacology, Bromatology and Toxicology, Faculty of Pharmacy and \\ Biochemistry, Universidad Nacional Mayor de San Marcos, Jr. Puno 1002, Lima 1501, Peru \\ ${ }^{2}$ Department of Biochemistry, Faculty of Pharmacy and Biochemistry, Universidad Nacional Mayor \\ de San Marcos, Jr. Puno 1002, Lima, Peru
}

Article history:

Received: 8 May 2020

Received in revised form: 2

July 2020

Accepted: 16 July 2020

Available Online: 5

September 2020

Keywords:

Waltheria ovata,

Response surface

methodology,

Antioxidant,

Polyphenols,

Spectrophotometry.

DOI:

https://doi.org/10.26656/fr.2017.4(6).211

\section{Introduction}

Natural antioxidants obtained from plant materials (flowers, leaves, roots, fruits and other parts) by different extraction techniques are mainly polyphenols (anthocyanins, phenolic acids, flavonoids, lignans and stilbenes), carotenoids (xanthophylls and carotenes) and vitamins (vitamin $\mathrm{A}, \mathrm{E}$ and $\mathrm{C}$ ) and other compounds (Pisoschi et al., 2016). Currently, there has been an increase of new methods to study the mechanisms of natural antioxidants from plant-based extracts or to measure its activity for use in the food, cosmetics and pharmaceutical industries (Xu et al., 2017).

Phytomedicine appears as a good alternative in modern times, where different types of chronic diseases such as cancer, diabetes, cardiovascular diseases, among others, are increasing day by day. In the traditional medicine from Ica, Peru, Waltheria ovata Cav. (Family: Sterculiaceae) is considered a rich source of antioxidants and other phytochemicals that have been reported to overcome some of the degenerative diseases that affect humans (Herrera-Calderon et al., 2016). Waltheria ovata is a shrub with open foliage. It has wrinkled pale bluishgreen leaves. The stems are dark red and flowers are small of yellow color. It is known as "lucraco" and roots are used in the treatment of diarrhea, pain, inflammation, and spasm (Herrera-Calderon et al., 2018). In addition, Waltheria ovata exhibits anti-carcinogenic, antibacterial, antioxidant, analgesic and anti-inflammatory properties (Bussmann and Glenn, 2010). In traditional medicine, infusion of leaves and flowers is used to combat pathology conditions respiratory like cold and cough. Among the inhabitants of Ica, its use is very widespread lucraco root cooking, to combat inflammation of the prostate.

The total phenolic content and antioxidant activity of ethanolic extract of lucraco can be affected by many factors including solvent, solvent/sample ratio, 
temperature and extraction time. Under different conditions in the laboratory, where multiple variables may influence the effect of tested products, response surface methodology (RSM) is an effective technique to determine the most favorable conditions of the independent variables in view of a profitable process (Lee et al., 2013).

RSM was published by Box and Wilson in 1951 as a topic of chemical engineering (Şenaras, 2019). Generally, RSM is used to determine different factors that influence response and their interaction (Uysal et al., 2017; Kaleem et al., 2019). The advantages of using RSM are the evaluation of the effects of certain process variables and their interaction on response variables, less laboriousness, more speed, less cost, less number of required experiments and less time consumption. Furthermore, in many articles, RSM linked to foods and biotechnological processes proved to be a helpful tool, which allows process optimization to be conducted effectively (Bassani et al., 2014; Hou et al., 2016).

The objective of the present work was to optimize the phenolic content and antioxidant activity under three factors such as solvent/sample ratio, temperature and extraction time of Waltheria ovata roots using the RSM.

\section{Materials and methods}

\subsection{Plant material}

W. ovata roots were collected, in April 2018 from Los Aquijes district, Ica, Peru. Authentication of the specimen was preserved (51-USM-2015), which was deposited at the Museum of Natural History of the Universidad Nacional Mayor de San Marcos, Lima, Peru.

\subsection{Chemicals and reagents}

2,2-diphenyl-1-picrylhydrazyl radical $(\mathrm{DPPH} \bullet$, Folin-Ciocalteu (FC) reagent, gallic acid, from SigmaAldrich (St. Louis, MO, USA) were used. Analytical grade ethanol, sodium carbonate and other chemical reagents were purchased from Merck Peruana (Ate, Lima, Peru).

Waltheria ovata was converted to powder using an electric grinder, packaged in polyethylene bags and kept in a dark place at room temperature.

\subsection{Extraction procedure}

The ethanolic extract of the root powder was obtained under different treatments of the central compound rotatable design for three independent variables (Table 1$)$.
The different extracts soaked with $96 \%$ ethanol were filtered through Whatman No. 1 filter paper and then centrifuged at $10,000 \mathrm{rpm}$ for 10 mins at $4^{\circ} \mathrm{C}$ until further use (Fattahi and Rahimi, 2016).

Table 1. Independent variable levels in experimental design for response surface analysis

\begin{tabular}{ccccccc}
\hline \multirow{2}{*}{ Symbol } & $\begin{array}{c}\text { Independent } \\
\text { variable }\end{array}$ & \multicolumn{5}{c}{ Factor level } \\
\cline { 3 - 7 } $\mathrm{X}_{1}$ & $\begin{array}{c}\text { Extraction time } \\
(\text { min) }\end{array}$ & 33 & 40 & 50 & 60 & 67 \\
$\mathrm{X}_{2}$ & $\begin{array}{c}\text { Solid/liquid ratio } \\
(\mathrm{g} / \mathrm{mL})\end{array}$ & $1: 03$ & $1: 10$ & $1: 20$ & $1: 30$ & $1: 37$ \\
$\mathrm{X}_{3}$ & $\begin{array}{c}\text { Temperature } \\
\left({ }^{\circ} \mathrm{C}\right)\end{array}$ & 33 & 40 & 50 & 60 & 67 \\
\hline
\end{tabular}

\subsection{Total polyphenols content}

TPC was estimated by spectrophotometric technique (Ainsworth and Gillespie, 2007). Thus, $300 \mu \mathrm{L}$ of sample extract was put into three tubes. Then, $1800 \mu \mathrm{L}$ distilled water was added to each test tube, and $450 \mu \mathrm{L}$ of eight-time diluted Folin-Ciocalteu reagent was added and allowed to stand for $5 \mathrm{mins}$ at room temperature. Finally, $450 \mu \mathrm{L}$ of $20 \%(\mathrm{w} / \mathrm{v})$ sodium carbonate was added to react for 60 mins. The absorbance was estimated at $760 \mathrm{~nm}$ with UV-VIS spectrophotometer. A standard curve of gallic acid $(1-7.5 \mu \mathrm{g} / \mathrm{mL})$ was used to measure the TPC and was expressed as gallic acid equivalent milligram per gram of dry extract (mg GAE/ g).

\subsection{Antioxidant activity}

1,1-Diphenyl-2-picrylhydrazyl (DPPH) radical scavenging activity of Waltheria ovata was determined according to the method developed by Aguilar-Felices et al. (2019). Antioxidant activity (AA) was expressed as percent of inhibition of DPPH radical (\%).

$$
\text { Antioxidant activity }(\%)=[(\mathrm{A} 0-\mathrm{A} 1) / \mathrm{A} 0] \times 100
$$

Where A0 is the absorbance of the control reaction (DPPH) and Al is the absorbance of the sample, corrected by the absorbance of the sample (blank).

\subsection{Statistical optimization}

\subsubsection{Experiments one factor at a time}

To evaluate the effect of each factor under extraction treatment on TPC and antioxidant activity of the extract from $W$. ovata roots, time (40,50 and $60 \mathrm{mins})$, material/ solvent ratio $(1: 10 ; 1: 20 ; 1: 30 \mathrm{~g} / \mathrm{mL})$, and temperature $\left(40,50\right.$, and $\left.60^{\circ} \mathrm{C}\right)$ were investigated as single factor experiments.

\subsubsection{Experimental design}

Response surface methodology was used to find the optimal condition of extraction. The three variables 
mentioned in the previous section were coded as $\mathrm{X}_{1}-\mathrm{X}_{3}$ according to Equation (1) and examined at five levels (Table 1).

$$
\mathrm{X}_{\mathrm{i}}=\frac{2 \cdot\left(\mathrm{X}_{\mathrm{i}}-\mathrm{X}_{\mathrm{icp}}\right)}{\Delta \mathrm{X}_{\mathrm{i}}}
$$

where $\mathrm{xi}$ is the coded level of the ith variable, $\mathrm{Xi}$ is the level of the ith natural variable, Xicp is the ith natural variable at the center point, and $\Delta \mathrm{Xi}$ is the step change value of the ith natural variable.

Table 2 presents the matrix of the three-variable central composite rotatable design with twenty experimental runs that were performed in a random order, including five genuine replicas at the center point.

The behavior of the analyzed responses is described by the following quadratic polynomial model:

$$
y=\beta_{0}+\sum_{i=1}^{3} \beta_{i} x_{i}+\sum_{i=1}^{3} \beta_{i i} x_{i}^{2}+\sum_{i<j} \sum \beta_{i j} x_{i} x_{j}
$$

where $Y$ is the response value; $\beta_{0}$ is a constant; $\beta \mathrm{i}$ is the linear regression coefficient; $\beta \mathrm{ii}$ is the quadratic regression coefficient; $\beta \mathrm{ij}$ is the interaction regression coefficient; $x i$ and $x j$ are the independent variables encoded.

\subsubsection{Statistical analysis}

The regression coefficients of the model were obtained by a multiple regression analysis on the experimental data using the least-squares method. The data analyses were performed using Statistica ${ }^{\circledR}$ (software system, StatSoft, Tulsa, USA), version 10.0. Differences were considered significant at $\mathrm{p}$-values $<$ 0.05 .

\section{Results and discussion}

The results of the central compound rotatable design to optimize the extraction process for the content of phenolic compounds and antioxidant activity of Waltheria ovata roots are presented in Table 2.

Figure 1 shows the Pareto chart for each response with all possible standardized effects at a 0.05 level of significance.

The effect of the variables (temperature, time and solid/liquid ratio) and their interactions are represented in Pareto charts. When the histograms which represent each variable cross the vertical line, they are considered as significant. According to Figure 1(a), total phenolic content is positively affected by temperature and time but negatively influenced by the quadratic effect of solid /liquid ratio. In Figure 1(b), antioxidant activity is positively affected by temperature, time and solid /liquid ratio and negatively influenced by the interaction between the variable: time and solid/liquid ratio.

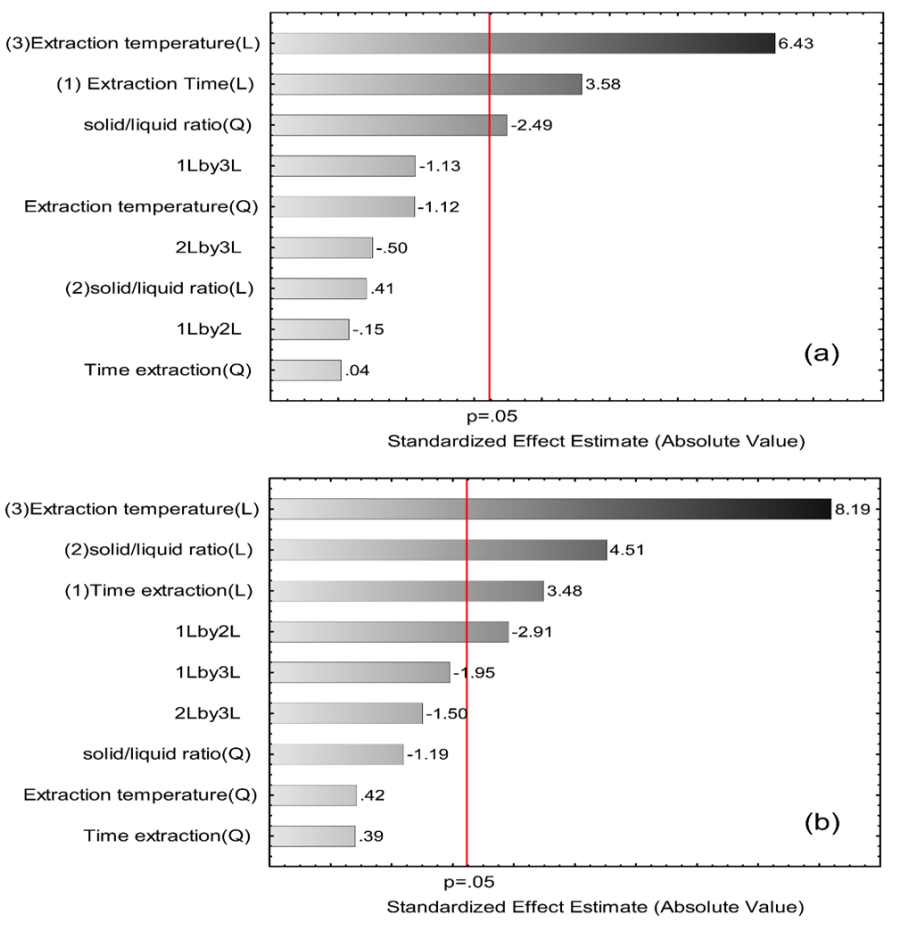

Figure 1. Pareto chart of the standardized effects for (a) total phenolic content (TPC) and (b) antioxidant activity (DPPH assay).

This implies that high levels of temperature and time favored both responses because they are variables that improve extraction yield in the leaching process. Meanwhile, the solid/liquid ratio had different effects on the responses. The quadratic effect for the total phenolic content implied that a concave surface was generated as a function of this variable (Figures 2(a) and (b)). Thus, this response was favored up to the level of the central point, and higher values of this variable decreased the total phenolic content. This is evident that the leaching of these compounds occurred with the increase in the dry matter of the roots until saturation. Then, a higher solid content generated diffusion restrictions for the leaching of phenolic compounds. In contrast, the high level of the solid/liquid ratio favored antioxidant activity. This phenomenon means that other compounds with antioxidant activity than phenolic compounds were extracted under these conditions, implying that the extraction conditions can modulate the isolation of fractions of antioxidant compounds.

An analysis of variance (ANOVA) for each reduced model was required to confirm the results shown in Figure 1 and the adequacy of the model. These results are presented in Tables 3 and 4 . As can be seen, the data provided are consistent with the Pareto charts.

$F$ and $p$ values give the significance for the coefficient terms of the model. Thus, the largest F-value and the smallest p-value imply that the term is most 
Table 2. Matrix of the central composite rotatable design and its experimental values in the total phenolic content (TPC) and antioxidant activity (AA)

\begin{tabular}{cccccccc}
\hline \multirow{2}{*}{ Run } & \multicolumn{3}{c}{ Factors } & \multicolumn{2}{c}{ Experimental values } & \multicolumn{2}{c}{ Predicted values } \\
\cline { 2 - 7 } & $\mathrm{X}_{1}$ & $\mathrm{X}_{2}$ & $\mathrm{X}_{3}$ & $\mathrm{TPC}(\mathrm{mg}$ GAE$/ \mathrm{g})$ & $\mathrm{AA}(\%)$ & $\mathrm{TPC}(\mathrm{mg}$ GAE/g) & AA (\%) \\
\hline 1 & -1 & -1 & -1 & $0.242 \pm 0.01$ & $45.50 \pm 1.5$ & 0.242 & 44.56 \\
2 & -1 & -1 & 1 & $0.419 \pm 0.01$ & $78.00 \pm 1.0$ & 0.384 & 74.87 \\
3 & -1 & 1 & -1 & $0.239 \pm 0.02$ & $70.00 \pm 2.0$ & 0.242 & 69.07 \\
4 & -1 & 1 & 1 & $0.368 \pm 0.02$ & $83.00 \pm 1.0$ & 0.384 & 90.02 \\
5 & 1 & -1 & -1 & $0.346 \pm 0.01$ & $71.00 \pm 1.2$ & 0.332 & 68 \\
6 & 1 & -1 & 1 & $0.445 \pm 0.01$ & $83.21 \pm 1.5$ & 0.422 & 86.16 \\
7 & 1 & 1 & -1 & $0.310 \pm 0.01$ & $69.23 \pm 2.0$ & 0.332 & 74.38 \\
8 & 1 & 1 & 1 & $0.411 \pm 0.01$ & $80.23 \pm 2.0$ & 0.422 & 83.19 \\
9 & -1.68 & 0 & 0 & $0.318 \pm 0.03$ & $67.23 \pm 1.0$ & 0.323 & 66.8 \\
10 & 1.68 & 0 & 0 & $0.433 \pm 0.03$ & $85.98 \pm 1.5$ & 0.431 & 80.76 \\
11 & 0 & -1.68 & 0 & $0.261 \pm 0.02$ & $57.50 \pm 1.5$ & 0.315 & 64.73 \\
12 & 0 & 1.68 & 0 & $0.365 \pm 0.01$ & $85.30 \pm 2.0$ & 0.315 & 82.83 \\
13 & 0 & 0 & -1.68 & $0.263 \pm 0.01$ & $58.00 \pm 2.0$ & 0.251 & 57.34 \\
14 & 0 & 0 & 1.68 & $0.431 \pm 0.02$ & $95.36 \pm 2.0$ & 0.446 & 90.22 \\
15 & 0 & 0 & 0 & $0.381 \pm 0.03$ & $75.01 \pm 1.5$ & 0.377 & 73.78 \\
16 & 0 & 0 & 0 & $0.382 \pm 0.02$ & $75.32 \pm 1.0$ & 0.377 & 73.78 \\
17 & 0 & 0 & 0 & $0.384 \pm 0.02$ & $76.00 \pm 1.0$ & 0.377 & 73.78 \\
18 & 0 & 0 & 0 & $0.404 \pm 0.02$ & $75.20 \pm 1.0$ & 0.377 & 73.78 \\
19 & 0 & 0 & 0 & $0.379 \pm 0.03$ & $73.00 \pm 2.0$ & 0.377 & 73.78 \\
20 & 0 & 0 & 0 & $0.332 \pm 0.01$ & $69.52 \pm 1.0$ & 0.377 & 73.78 \\
\hline
\end{tabular}

Table 3. Analysis of variance of the quadratic model for optimization of total phenolic content from $W$. ovata roots

\begin{tabular}{lccccc}
\hline \multicolumn{1}{c}{ Factor } & SS & df & MS & F-value & Probability- $\mathrm{p}^{\mathrm{a}}$ \\
\hline Time extraction (L) & 0.014106 & 1 & 0.014106 & 17.19021 & 0.000989 \\
Solid/liquid ratio (Q) & 0.006884 & 1 & 0.006884 & 8.38923 & 0.011725 \\
Extraction temperature (L) & 0.045495 & 1 & 0.045495 & 55.4424 & 0.000003 \\
Extraction temperature (Q) & 0.001392 & 1 & 0.001392 & 1.69659 & 0.213754 \\
Time extraction (L) x Extraction Temp (L) & 0.00141 & 1 & 0.00141 & 1.71806 & 0.211038 \\
Error & 0.011488 & 14 & 0.000821 & & \\
Lack of fit & 0.008663 & 9 & 0.000963 & 1.70367 & 0.289208 \\
Pure error & 0.002825 & 5 & 0.000565 & & \\
Total sum of squares & 0.080279 & 19 & & & \\
\hline
\end{tabular}
$\mathrm{R}^{2}=0.86 . \mathrm{F}$-value $>\mathrm{F}_{0.05}(1,14)$ tabular $=4.60 .{ }^{\mathrm{a}}$ Significant for $\mathrm{p}$-values $<0.05$.

Table 4. Analysis of variance of quadratic model for optimization of antioxidant activity from $W$. ovata roots by using DPPH assay

\begin{tabular}{lccccc}
\hline \multicolumn{1}{c}{ Factor } & SS & df & MS & F-value & Probability- $\mathrm{p}^{\mathrm{a}}$ \\
\hline Time extraction (L) & 235.435 & 1 & 235.435 & 13.20106 & 0.003032 \\
Solid/liquid ratio (L) & 395.612 & 1 & 395.612 & 22.18234 & 0.000408 \\
Extraction temperature (L) & 1305.821 & 1 & 1305.821 & 73.21862 & 0.000001 \\
Time extraction (L) x Solid/liquid ratio (L) & 164.258 & 1 & 164.258 & 9.21009 & 0.009576 \\
Time extraction (L) x extraction temperature (L) & 73.751 & 1 & 73.751 & 4.13526 & 0.062936 \\
Solid/liquid ratio (L) x Extraction temperature (L) & 43.758 & 1 & 43.758 & 2.45355 & 0.141269 \\
Error & 231.849 & 13 & 17.835 & & \\
Lack of fit & 202.577 & 8 & 25.322 & 4.3252 & 0.06175 \\
Pure error & 29.272 & 5 & 5.854 & & \\
Total sum of squares & 2450.483 & 19 & & & \\
\hline
\end{tabular}

$\mathrm{R}^{2}=0.86 . \mathrm{F}$-value $>\mathrm{F}_{0.05}(1,14)$ tabular $=4.60 .{ }^{\mathrm{a}}$ Significant for $\mathrm{p}$-values $<0.05$. 
significant to the model. Hence, the linear effects of $X_{1}$, $\mathrm{X}_{2}$, and $\mathrm{X}_{3}$ for the TPC and AA responses, the quadratic effect of $X_{2}$ for the TPC response, and the $X_{1} X_{2}$ interaction for the AA response had p-values less than 0.05 , proposing that the model could be used to predict these responses.

Lack of fit gives the variation of the data around the fitted model. For the TPC model, the F and $\mathrm{p}$ values were 1.70 and 0.289 , respectively. For the AA model, the $\mathrm{F}$ and $\mathrm{p}$ values were 4,325 and 0.0617 , respectively. This implies that the lack of fit is not significant for both responses.

The goodness of the reduced model fit was verified by the coefficient of determination $\mathrm{R}^{2}$, which were 0.86 and 0.91 for TPC and AA, respectively. Approximately, $100 \mathrm{R}^{2}=86 \%$ and $91 \%$, of the variability of the observed responses can be explained by the fitted models in the coded form of Eqs. (3) and (4), which were obtained by multiple regression on the experimental data using the least-squares method as shown below for TPC:

$\mathrm{y}=0.377+0.032 \mathrm{x}_{1}-0.022 \mathrm{x}_{2}^{2}+0.058 \mathrm{x}_{3}-0.01 \mathrm{x}_{3}^{2}-0.013 \mathrm{x}_{1} \mathrm{x}_{3}$

whilst for antioxidant activity (AA) the regression coefficients of the model are stated as:

$\mathrm{y}=73.78+4.152 \mathrm{x}_{1}+5.382 \mathrm{x}_{2}+9.778 \mathrm{x}_{3}-4.531 \mathrm{x}_{1} \mathrm{x}_{2}-3.036 \mathrm{x}_{1} \mathrm{x}_{3}-2.339 \mathrm{x}_{2} \mathrm{x}_{3}$

Note that; $\mathrm{X}_{1}$ : time extraction, $\mathrm{X}_{2}$ : solid/liquid ratio and $\mathrm{X}_{3}$ : temperature extraction

3D response surface plots help to understand the effect of the study variables on the response variable as shown in Figure 2. As can be seen, the increase in temperature in the range of $50-67^{\circ} \mathrm{C}$ favored the extraction of the phenolic compound content and antioxidant activity. However, a further increase in temperature could cause a decrease in the phenolic compound content and thus in antioxidant activity. Likewise, the extraction time between 60 and 70 mins increased the extraction of phenolic compounds and antioxidant activity. Figures 2(a) and (c) show that the material/ solvent ratio had a maximum response value at the central level for the phenolic compound content, while it had a linear effect for antioxidant activity. Therefore, the validation experiment was carried out under the experimental conditions that favored both responses as shown in Table 5. The results indicate a good prediction of the model in the experimental region.
The antioxidant activity of plants is generally attributed to phenolic compounds and their derivatives such as phenolic acids, flavonoids, isoflavonoids, flavanones, flavones, anthocyanins, among others. However, several factors play a critical role during the isolation of phenolic compounds with antioxidant activity from plant materials (Liyana-Pathirana and Shahidi, 2005; Ghafoor et al., 2009). Numerous reports confirm that aqueous mixtures of organic solvents are the most suitable for extraction of phenolic compounds from plant sources, in our study the solvent was $96 \%$ ethanol and showed a better phenolic content compared to a water-ethanol (3:7) extraction. Although, this can vary, depending on the plant material and type of species (Ilghami et al., 2015; Chen et al., 2018). Based on many reports and studies of the toxicity of solvents, ethanol was selected as the main solvent instead of methanol, propanol and other which is considered much safer to extract phytochemicals as antioxidants (Belwal et al., 2016; Wani et al., 2017).

A relation between extraction time and TPC was established, wherein the increase in time of exposure showed the highest TPC. The extraction temperature only influenced on the antioxidant capacity when it was determined by DPPH assay but in others such as ABTS and FRAP were not significant (Cacace and Mazza, 2003). The interaction between temperature and extraction time could be explained by considering that at higher temperatures, and more time in the extraction process, the ethanol has a higher capacity to solubilize polyphenols and surface tension and solvent viscosity decreases with temperature, which will improve the penetration into the matrix by the solvent used.

\section{Conclusion}

Extraction is the main stage in the recovery and isolation of polyphenols and other antioxidant compounds from various plant-based materials, but the effective extraction of these compounds depends on the appropriate selection of the levels of various physical and chemical variables that interact with each other. Thus, the response surface methodology is a tool to maximize the content of these compounds in the extraction of $W$. ovata roots. Experimental conditions for maximum extraction were as follows: $60^{\circ} \mathrm{C}$, solid/ solvent ratio $1: 20 \mathrm{~g} / \mathrm{mL}$, and time of 60 mins. Under these optimum conditions, TPC was $0.448 \pm 0.02$

Table 5. Comparison between experimental and predicted values under optimum conditions for total phenolic content (TPC) and antioxidant activity (AA)

\begin{tabular}{|c|c|c|c|c|c|}
\hline \multirow{2}{*}{ Response variable } & \multicolumn{3}{|c|}{ Optimum conditions } & \multirow{2}{*}{$\begin{array}{c}\text { Experimental } \\
\text { values }\end{array}$} & \multirow{2}{*}{$\begin{array}{c}\text { Predicted } \\
\text { values }\end{array}$} \\
\hline & Time (min) & Solid/liquid ratio $(\mathrm{g} / \mathrm{mL})$ & Temperature $\left({ }^{\circ} \mathrm{C}\right)$ & & \\
\hline TPC (mg GAE/g) & 60 & $1: 20$ & 60 & $0.448 \pm 0.02$ & 0.444 \\
\hline AA $(\%)$ & 60 & $1: 20$ & 60 & $87.00 \pm 2.0$ & 84.67 \\
\hline
\end{tabular}


(a)

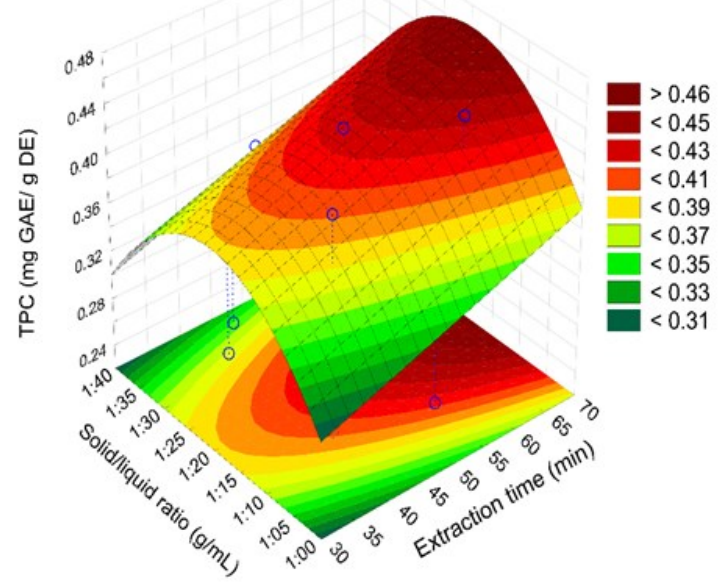

(c)
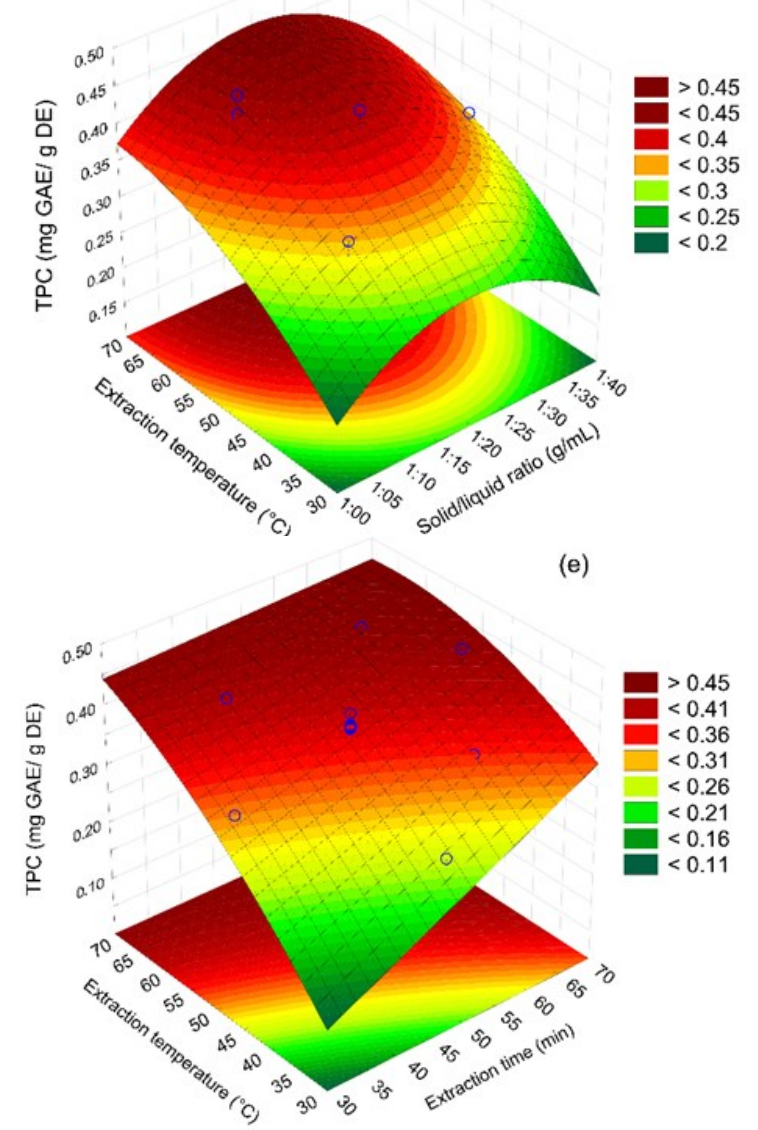

(b)

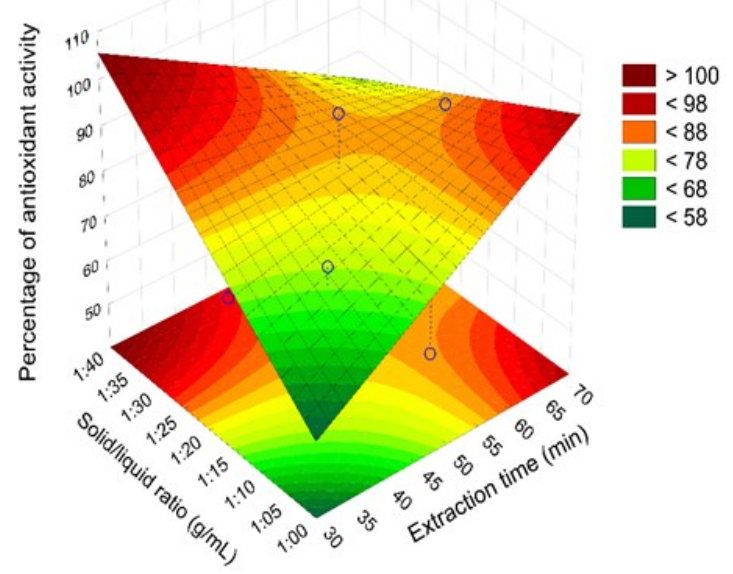

(d)

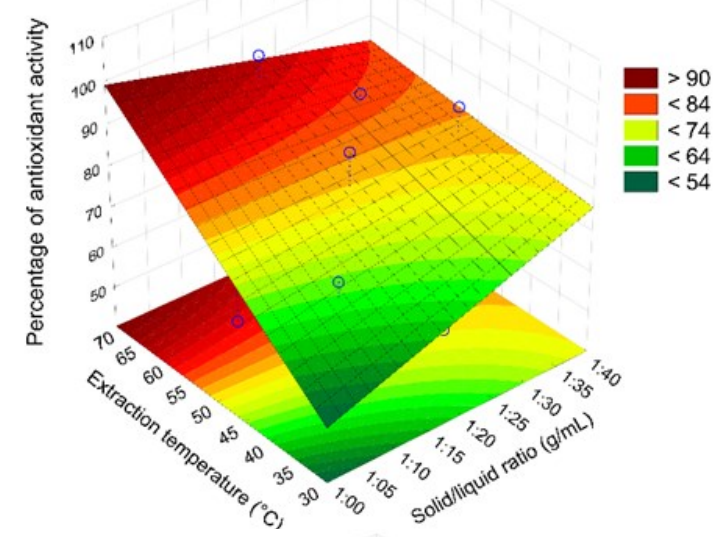

(f)

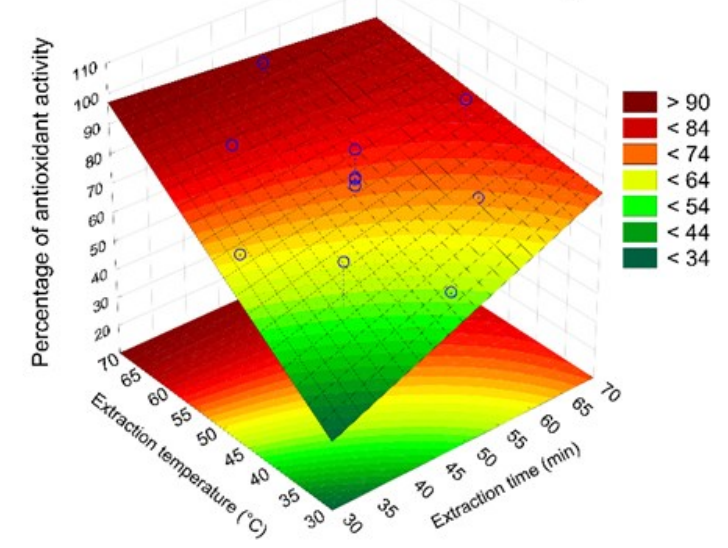

Figure 2. Response surfaces and contour plots for TPC: Total phenolic content (mg GAE/g) and AA: antioxidant activity (\%). Extraction temperature was $60^{\circ} \mathrm{C}$ (Figures (a) and (b)). Extraction time was 60 mins (Figures (c) and (d)) and solid/liquid ratio was 1:20 (Figures (e) and (f))

mgGAE/g and DPPH radical scavenging activity was $87.00 \pm 2.0 \%$. The results of the validation experiment are consistent with those predicted by the models.

\section{Conflict of interest}

The authors declare no conflict of interest.

\section{Acknowledgments}

This research was supported by the Project A19040013 (RR No 05129-R-19) of "Vicerrectorado de Investigación y Posgrado" of the Universidad Nacional
Mayor de San Marcos (Lima-Peru).

\section{References}

Aguilar-Felices, E.J., Romero-Viacava, M., EncisoRoca, E., Herrera-Calderon, O., Común-Ventura, P., Yuli-Posadas, R.Á., Chacaltana-Ramos, L. and PariOlarte, B. (2019). Antioxidant Activity of the Germinated Seed of Four Varieties of Amaranthus caudatus L. From Peru. Pharmacognosy Journal, 11 (3), 588-593. https://doi.org/10.5530/pj.2019.11.94

Ainsworth, E.A. and Gillespie, K.M. (2007). Estimation 
of total phenolic content and other oxidation substrates in plant tissues using Folin-Ciocalteu reagent. Nature Protocols, 2(4), 875-877. https:// doi.org/10.1038/nprot.2007.102

Bassani, D.C., Nunes, D.S. and Granato, D. (2014). Optimization of phenolics and flavonoids extraction conditions and antioxidant activity of roasted yerbamate leaves (Ilex paraguariensis A. St.-Hil., Aquifoliaceae) using response surface methodology. Anais Da Academia Brasileira de Ciencias, 86(2), 923-933. https://doi.org/10.1590/00013765201420130019

Belwal, T., Dhyani, P., Bhatt, I.D., Rawal, R.S. and Pande, V. (2016). Optimization extraction conditions for improving phenolic content and antioxidant activity in Berberis asiatica fruits using response surface methodology (RSM). Food Chemistry, 207, 115-124. https://doi.org/10.1016/ j.foodchem.2016.03.081

Bussmann, R.W. and Glenn, A. (2010). Medicinal plants used in Northern Peru for reproductive problems and female health. Journal of Ethnobiology and Ethnomedicine, 6, 30. https://doi.org/10.1186/17464269-6-30

Cacace, J.E. and Mazza, G. (2003). Optimization of extraction of anthocyanins from black currants with aqueous ethanol. Journal of Food Science, 68(1), 240-248. https://doi.org/10.1111/j.13652621.2003.tb14146.x

Chen, S., Zeng, Z., Hu, N., Bai, B., Wang, H. and Suo, Y. (2018). Simultaneous optimization of the ultrasound-assisted extraction for phenolic compounds content and antioxidant activity of Lycium ruthenicum Murr. fruit using response surface methodology. Food Chemistry, 242, 1-8. https://doi.org/10.1016/j.foodchem.2017.08.105

Fattahi, M. and Rahimi, R. (2016). Optimization of Extraction Parameters of Phenolic Antioxidants from Leaves of Capparis spinosa Using Response Surface Methodology. Food Analytical Methods, 9(8), 23212334. https://doi.org/10.1007/s12161-016-0414-9

Ghafoor, K., Choi, Y. H., Jeon, J.Y. and Jo, I.H. (2009). Optimization of ultrasound-assisted extraction of phenolic compounds, antioxidants, and anthocyanins from grape (Vitis vinifera) seeds. Journal of Agricultural and Food Chemistry, 57(11), 49884994. https://doi.org/10.1021/jf9001439

Herrera-Calderon, O., Alvarado-Puray, C., ArroyoAcevedo, J., Rojas-Armas, J., Chumpitaz-Cerrate, V., Hañari-Quispe, R. and Valenzuela-Herrera, R. (2018). Phytochemical screening, total phenolic content, antioxidant, and cytotoxic activity of five peruvian plants on human tumor cell lines.
Pharmacognosy Research, 10(2), 161-165. https:// doi.org/10.4103/pr.pr_109_17

Herrera-Calderon, O., Enciso-Roca, E., Pari-Olarte, B. and Arroyo-Acevedo, J. (2016). Phytochemical screening, antioxidant activity and analgesic effect of Waltheria ovata Cav. roots in mice. Asian Pacific Journal of Tropical Disease, 6(12), 1000-1003. https://doi.org/10.1016/S2222-1808(16)61172-6

Hou, W., Zhang, W., Chen, G. and Luo, Y. (2016). Optimization of extraction conditions for maximal phenolic, flavonoid and antioxidant activity from Melaleuca bracteata leaves using the response surface methodology. PLOS ONE, 11(9), e0162139. https://doi.org/10.1371/journal.pone.0162139

Ilghami, A., Ghanbarzadeh, S. and Hamishehkar, H. (2015). Optimization of the ultrasonic-assisted extraction of phenolic compounds, ferric reducing activity and antioxidant activity of the Beta vulgaris using response surface methodology. Pharmaceutical Sciences, 21(1), 46-50. https:// doi.org/10.15171/PS.2015.16

Kaleem, M., Ahmad, A., Amir, R.M. and Raja, G.K. (2019). Ultrasound-assisted phytochemical extraction condition optimization using response surface methodology from perlette grapes (Vitis vinifera). Processes, 7(10). https://doi.org/10.3390/ pr7100749

Lee, L.S., Lee, N., Kim, Y.H., Lee, C.H., Hong, S.P., Jeon, Y.W. and Kim, Y.E. (2013). Optimization of ultrasonic extraction of phenolic antioxidants from green tea using response surface methodology. Molecules, 18(11), 13530-13545. https:// doi.org/10.3390/molecules 181113530

Liyana-Pathirana, C. and Shahidi, F. (2005). Optimization of extraction of phenolic compounds from wheat using response surface methodology. Food Chemistry, 93(1), 47-56. https:// doi.org/10.1016/j.foodchem.2004.08.050

Pisoschi, A.M., Pop, A., Cimpeanu, C. and Predoi, G. (2016). Antioxidant capacity determination in plants and plant-derived products: A review. Oxidative Medicine and Cellular Longevity, 2016, 9130976. https://doi.org/10.1155/2016/9130976

Şenaras, A.E. (2019). Parameter optimization using the surface response technique in automated guided vehicles. In Kumar, K., Zindani, D. and Davim, P. (Eds.). Sustainable Engineering Products and Manufacturing Technologies, p. 187-197. USA: Academic Press. https://doi.org/10.1016/B978-0-12816564-5.00008-6

Uysal, S., Cvetanović, A., Zengin, G., Đurović, S. and Aktumsek, A. (2017). Optimization of the extraction 
process of antioxidants from loquat leaves using response surface methodology. Journal of Food Processing and Preservation, 41(5). https:// doi.org/10.1111/jfpp.13185

Wani, S.M., Jan, N., Wani, T.A., Ahmad, M., Masoodi, F.A. and Gani, A. (2017). Optimization of antioxidant activity and total polyphenols of dried apricot fruit extracts (Prunus armeniaca L.) using response surface methodology. Journal of the Saudi Society of Agricultural Sciences, 16(2), 119-126. https://doi.org/10.1016/j.jssas.2015.03.006

Xu, D.P., Li, Y., Meng, X., Zhou, T., Zhou, Y., Zheng, J., Zhang, J.J. and Li, H.-B.. (2017). Natural antioxidants in foods and medicinal plants: Extraction, assessment and resources. International Journal of Molecular Sciences, 18(1), 96. https:// doi.org/10.3390/ijms18010096 